\title{
CONSIDERACIONES PRELIMINARES A UN ESTUDIO DEL REGIMEN LEGAL DE LAS INVERSIONES EXTRANJERAS EN EL PERU
}

\author{
1. Introducción. 2. Clases de Inversiones: directas, \\ indirectas y en cartera. 3. Composición de las inver- \\ siones. 4. Carácter "extranjero" de las inversiones. \\ 5. Ventajas y desventajas reconocidas a las inversiones \\ extranjeras. 6. Conclusión.
}

\section{Introducción}

Los países en vías de desarrollo, ante la permanente insuficiencia de capitales locales para financiar sucrecimiento, se ven precisados a recurrir a fuentes externas de inversión. Estas van a permitirles alcanzar un nivel de vida aceptable para sus habitantes y cambiar los términos de su relación de dependencia hacia los países altamente industrializados. Se considera por eso a las inversiones extranjeras, con el comercio internacional, como dos de los puntos de apoyo fundamentales para el despegue económico. En el Perú, todavia no hay cifras disponibles que permitan conocer con exactitud la proporción que en la actualidad corresponde al capital extranjero en el total de inversiones del país (1), ni el papel que está desempeñando dentro del panorama general de la economia, pero se ha estimado que las necesidades de inversión externa para el período 1971-1975, alcanzan la suma de un mil cien millones de dólares (2).

Por otra parte, para los inversionistas de las naciones económicamente más desarrolladas, que no siempre ob-

1. Las cifras que da el Banco Central de Reserva del Perú, en la Reseña Económica y Financiera No 18, de Mayo-Junio de 1967, no son utilizables para este propósito porque son parciales y porque el criterio que se sigue para determinar las inversiones extranjeras no es igual al de las leyes peruanas sobre la materia, que son posteriores sino al clasificador de Balanza de Pagos del Fondo Monetario Internacional.

2. Diario "El Comercio" de 6 de Marzo de 1971, p. 1, Declaraciones del Ministro de Economía y Finanzas, General Francisco Morales Bermúdez. tienen rendimientos muy altos en sus propios países, debido a la exorbitante alza de los costos de producción, también resulta ampliamente rentable invertir en paises donde éstos son comparativamente más bajos (3); además de la consideración ulterior de que las inversiones a largo plazo en el extranjero son convenientes, deside un punto de vista de seguridad, y necesarias para mantener un alto nivel de exportación de bienes y servicios. Es un hecho que uno de los mayores renglones de ingresos de muchas compañias inversionistas está constituido por el producto de los suministros de insumos a su filiales de ultramar. En el informe presentado al Presidente de los Estados Unidos de América por la Comisión Williams, acerca de la politica oficial sobre inversiones y comercio internacional, se afirma que las actividades en el extranjero de empresas norteamericanas producen exportaciones considerables de ese país en bienes de capital, repuestos y productos relacionados; y que en 1965 el $25 \%$ del total de las exportaciones no agrícolas de los Estados Unidos de América se produjeron debido a esta causa (3a).

\section{Clases de Inversiones: directas, indirectas y en cartera}

Una manera en que se canaliza esta corriente internacional de capitales que representan las inversiones es mediante la contratación de créditos, que pueden revestir la forma de préstamos de entidades internacionales, gobiernos extranjeros, o banca privada ex-

3. Diario "La Prensa" de 20 de Junio de 1971. Declaraciones del Presidente de la Asociación de la Industria Química Alemana a la Agencia de Noticias Ansa.

3a. STANLEY D. MERTZGER. Developments in the Law and Institutions of International Economic Relations. American Journal of International Law. Vol. 66 1972 p. 542. 
iranjera, a organismos públicos; o de crédito privado otorgado a individuos o empresas particulares en forma de préstamos o suscripciones de bonos. Con esta modalidad quienes suministran el capital no corren otro riesgo que el inherente a cualquier operación de crédito, a cambio de beneficios que varían de acuerdo a las tasa de interés pero que en ningún caso llevan consigo poder de decisión o control sobre las actividades de los receptores de la inversión. Esta forma es una de las dos que puede revestir la inversión exiranjera, y es la denominada inversión indirecta o e.l cartera (4).

Quien realiza una inversión indirecta, lo hace concediendo un préstamo o comprando un bono que van a obtener un rendimiento fijo, y generalmente moderado, independientemente de la buena o mala marcha del negocio. En un mundo en convulsionada transformación, en que las naciones pobres toman conciencia, cada vez con mayor celo, de sus derechos y

4. El criterio del "riesgo" como factor determinante para decidir si una inversión es directa o indirecta -es decir si el rendimiento de la inversión depende o no del éxito del negocio- es adoptado een textos legales como las decisiones 24 y 37, sobre Régimen Común de Tratamiento de los Capitales Extranjeros de la Comisión del Acuerdo de Cartagena, aprobado dentro del marco del Grurú en 1970; -y por Venezuela en 1973 por el artículo po Andino, por Bolivia, Colombia, Chile, Ecuador y Pe$1^{\text {}}$ de la Ley sobre Inversión del Capital Extranjero de Indonesia, de 10 de Enero de 1967; y por autores como CARLOS POSADA URIBE. Estatuto legal para las inversiones Extranjeras en Colombia, Bogotá, 1966. p. 11. El criterio del "Control", según el cual las colocaciones en valores que no entrañan el control de las instituciones, como en el caso de los accionistas minoritarios - aunque lleven consigo riesgo- constituyen inversiones indirectas, es favorecido por organismos como el Fondo Monetario Internacional y por algunos autores: Ver INTERNATIONAL MONETARY FUND. Balance of Payments Manual. Washington, 1970. Third Edition. p. 175; NACIONES UNIDAS. El Financiamiento Externo de América Latina. México, 1969. p. 129; RICARDO MENDEZ SILVA. El Régimen Jurídico de las Inversiones Extranjeras en México. México 1969, p. 13; E. I. NWOGUGU. Foreign Investment in Developing Countries. Manchester, 1965. p. 4. Sin embargo la determinación del control sobre una compañía puede llegar a revestir procedimientos bastante sofisticados para concluir en algunos casos, que es suficiente para al fin el $25 \%$ y aún menos de las acciones. prerrogativas, esta forma de inversión, que evita muchas de las fricciones que causan las inversiones extranjeras, encuentran un número de partidarios que va en aumento. Como se hizo notar en un informe de las Naciones Unidas, de hace ya algunos años (5), "las inversiones de cartera, que habian ido disminuyendo gradualmente después de 1930 cuando constituían la forma predominante de inversión han recobrado impulso últimamente". Con posteridad al informe la tendencia ha ido en aumento. Pero aun asi, las inversiones indirectas o en cartera no representan, en el total de inversiones, un porcentaje lo suficientemente alto como para satisfacer la creciente demanda de capital de los países en desarrollo y por otro lado, las utilidades que rinden tampoco parecen ser suficientes, para los inversionistas, quienes están dispuestos a correr riesgos mayores a cambio de una ganancia más sustancial.

Para cumplir con tal propósito los grandes inversionistas, -generalmente compañías- optan por la modalida de constituir sucursales o subsidiarias locales (6) para ejercer actividades en forma permanente; $y$ los medianos y pequeños accionistas, sean sociedades de fondos mutuos o individuos particulares, se convierten en accionistas de empresas locales, asumiendo los riesgos anexos al resultado incierto del negocio, pero interviniendo en la marcha de la empresa, $y$, en el caso de los accionistas mayoritarios, ejerciendo control absoluto sobre ésta. Tal forma de inversión, que representa la mayor parte del capital privado externo en el Perú, es la llamada inversión extranjera directa (7), cuyo régimen legal es materia del presente trabajo. Su importancia dentro del porcentaje total de inversiones ha oscilado, entre 1956 y 1964, del $4.6 \%$ como mínimo en 1963 hasta el $21.1 \%$ como máximo en 1958 (8), habiendo aumentado el monto de la inversión proveniente de los Estados Unidos -que en el Perú es la mayor por paises- de 446 millones de dólares en 1960 a 545 millones en 1966

5. NACIONES UNIDAS. La Corriente Internacional de Capitales Privados 1956-58 Nueva York, 1959, p. 2. 6. Señaladas éstas, incidentalmente, como uno de los medios para eludir las barreras tarifarias de las comunidades económicas; ver, Clive Schmitthoff. The Export Trade. London, 5th edition.

7. Ver ibid, nota (4).

8. Instituto Nacional de Planificación, la Evolución de la Economía en el Período 1950-1964. Vol. III. Cap. V. 7C-Lima, 1966. 
(9). Al mes de marzo de 1973, la inversión extranjera directa registrada en el Ministerio de Economia y Finanzas, alcanzó la suma de treintaitrés mil, ochocientos noventaisiete millones, quinientos cuarentaitres mil, cuatrocientos noventajocho soles. Sin embargo, esta cifra es inferior al monto real debido, principalmente, a que muchos inversionistas no han cumplido aún con el requisito del registro debido a dificultades de diverso carácter.

\section{Composición de las Inversiones}

El aporte de la inversión extranjera directa, puede estar conformada por diversos elementos. En primer lugar puede estar constituido por moneda extranjera (10), que no forme parte de los recursos de moneda extranjera del país (11) y que, como requiere el artículo $1^{\circ}$ del Régimen Común de Tratamiento a los $\mathrm{Ca}$ pitales Extranjeros de la Comisión del Acuerdo de Cartagena, sea en moneda libremente convertible. El término de moneda convertible tiene aquí el significado de moneda comúnmente aceptada en transacciones internacionales; pero como en las actuales circunstancias el artículo VIII del Convenio Constitutivo del Fondo Monetario Internacional no es suficiente para determinar la convertibilidad de una moneda, es recomendable consultar, llegado el caso, al Banco Central de Reserva. La inversión de capital en divisas sin embargo, no parece ser proporcionalmente tan grande como podria esperar, según se indica más adelante.

La inversión puede realizarse asimismo en moneda nacional, pero, siempre que provenga de recursos con derecho a ser remitidos al exterior, es decir, que den-

9. Banco Central de Reserva. Reseña Económica y Financiera No 18. Mayo-Junio 1967. Cuadro XXI.

10. Conforme se reconoce, en el Perú, desde el Decreto-Ley No 18350, Parte Cuarta C, y luego en el DecretoLey No 18810, Parte Sexta D; así como en otros países, la Ley No 4131 modificada por la Ley $N^{\circ}$ 4390, de Brasil, Artículo 1; Ley sobre Incentivos y Garantías para la Inversión No 5186, de Filipinas, Sección 3, e); Foreign Investments (Protection) Act, 1964, de Uganda, Sección 5.1); Foreign Investments Protection Act, 1964, de Kenya, Sección 2.1); Decreto-Ley No 2-63 de 14 de febrero de 1963, de Viet-Nam, Artículo 5, 2a). Ley No 19151, artículo 2. a), de Argentina.

11. De acuerdo a lo que expresa la Ley de Inversión de Capital Extranjero, de Indonesia, promulgada el 10 de enero de 1967, artículo 2, a. tro del actual régimen de control de cambios la moneda nacional que se invierte esté comprendida dentro de los casos susceptibles de conversión a moneda extranjera. Aunque esta segunda modalidad, de evidente conveniencia por el ahorro que representa en el trámite administrativo, no fue reconocida en el Perú sino indirectamente en los Reglamentos de la Ley General de Industrias de 1970, y de la Ley General de Pesquería de 197i, ha sido posteriormente incorporada de manera explícita en la legislación peruana, mediante el Decreto-Ley No 18900, que puso en vigencia el Régimen Común de Tratamiento a los Capitales Extranjeros de la Comisión del Acuerdo de Cartagena (12).

El término "moneda nacional con derecho a ser remitida al exterior" se ha prestado a varias interprelaciones. Por un lado dentro de una interpretación parcial, pero difundida y considerando aisladamente el artículo 37 del Régimen Común, se ha intentado entender como tal sólo las utilidades hasta un catorce por ciento de la inversión, o por porcentajes mayores si estuvieran comprendidas entre las excepciones que prevé la ley a este tope. Pero, dentro del contexto general del Régimen, del Decreto-Ley No 18275 y su reglamento y de la legisiación peruana, un extranjero que se retira del país tiene derecho a llevarse con él todo el producto de sus rentas por diversos conceptos y en consecuencia todo capital de un extranjero constituye en sentido completo del término, "recursos con derecho a ser remitidos al exterior" (13). El Comité de Inversiones y Tecnologias Extranjeras del Ministerio de Economía y Finanzas ha adoptado esta última interpretación al registrar las inversiones extranjeras.

La inversión extranjera en moneda nacional constituye por lo general, lo que comúnmente se conoce como reinversión (14), y la capitalización de los créditos, tal como se consigna en forma expresa, en el artículo 2 de la Ley Argentina № 19151. Con rela-

12. También contiene dispositivos semejantes, Indonesia, Lex. cit. artículo 2 , c.

13. Artículo 72 del Decreto Supremo 004-71-EF. Artículos 8 y 9 del Régimen Común.

14. Aunque criterios más estrictos, como el Régimen Común del Acuerdo de Cartagena en su artículo $1^{\circ}$ consideran como "reinversión" únicamente la realizada en la misma empresa que haya generado las utilidades. El resto del aporte en moneda nacional sería simplemente "inversión". 
ción a la primera, según se ha observado, refiriéndose a la inversión proveniente de Estados Unidos (15), "de una salida de capital de 8,200 millones de dólares para inversiones directas, sólo cerca de 1,900 millones parecen corresponder a "nuevo" capital, mientras que unos 2,600 millones corresponden a utilidades reinvertidas por sucursales de empresas de Estados Unidos y 3,700 millones a reinversiones análogas de las filiales extranjeras de tales empresas". En el Perú, según datos recopilados por el Departamento de Comercio de los Estados Unidos (16), los porcentajes parecen haber sido inversos. Las entradas netas del capital norteamericano sumaron en el período 1960-1963, 48 millones de dólares, y la reinversión de utilidades no distribuidas sólo 12 millones de dólares. Sin embargo, estas cifras podrían variar, hacia un aumento de las reinversiones, a partir de la promulgación de las leyes de Reforma Agraria en 1969, y Ley General de Industrias en 1970, normas que contienen dispositivos diseñados para incrementar las reinversiones de las utilidades y del capital.

Las reinversiones en una misma empresa podrán ser admitidas por el gobierno sin necesidad de autorización, hasta por un monto que no exceda, anualmente, del cinco por ciento del capital de la empresa, según el artículo 13 del Régimen Común de Tratamiento a los Capitales Extranjeros. Para el caso de reinversiones por encima de ese porcentaje deberá contarse con autorización expresa como si se tratara de una inversión nueva.

Puede también estar constituido el aporte del capital por bienes adquiridos mediante el gasto de moneda extranjera que no forme parte de los recursos del país (17), es decir, bienes importados sin la co-

15. NACIONES UNIDAS. La Corriente Internacional de Capitales Privados, 1946-52, Nueva York, 1954, p. 13. Apreciaciones semejantes se encuentran para períodos posteriores en: NACIONES UNIDAS. La Corriente Internacional de Capitales privados 1956-58. Nueva York, 1959 , p. 23.

16. Ciado por Miguel Wionczek. Problemas involucrados en el Establecimiento de un Trato Común para la Inversión Extranjera en el Mercado Común Andino (Mimeo) 1970. p. 22.

17. En el Perú, tanto el Decreto-Ley No 18350, Parte Cuarta C, como el Decreto-Ley No 18810, Parte Sexta $\mathrm{D}$, utilizan la descripción de "activos tangibles rentables". Para otros países ver: Kenya, Lex cit. Sección 2. (1); Uganda, Lex cit. Sección 5. (1). rrespondiente salida de divisas (18). Estos bienes pueden ser plantas industriales, maquinaria, equipos, instrumentos o repuestos (19). En el Régimen Común de Tratamiento a los Capitales Extranjeros los términos "equipos" y "repuestos" itenen connotaciones bastante amplias, pues, a juzgar por el Anexo № 1 de dicho ordenamiento, se incluye como aportes de inversión las materias primas y productos intermedios, necesarios para la producción.

Algunas legislaciones consideran como inversión bienes cuya aceptación puede resultar discutible. Las Leyes de Kenya y Uganda, así como el Tratado para el estímulo a las inversiones entre la República Federal Alemana y la República Malgache de 21 de setiembre de 1962, comprenden como inversiones extranjeras acciones derechos o créditos (20). Sin embargo, no debe perderse de vista que la realización de los mismos puede ofrecer pocas posibilidades y tener un valor aparente e ilusorio, y sin embargo dar lugar a salida de utilidades.

Un bien cuya naturaleza elusiva hace difícil precisar si debe o no ser considerado como aporte de capital, y en consecuencia merece trato aparte, es la tecnología. En una encuesta realizada por la International Law Association entre sus miembros, que incluyen algunos juristas de países en vías de desarrollo, la mayoría de los entrevistados se manifestó a favor de incluir como capital el aporte técnico (21). En los Estados Unidos de América el U.S. Act 1961, sobre seguros a las inversiones, incluye como tales a las patentes, procesos y técnicas. Pero, como ha sido observado por Philippe Kahn, es evidente que estas clasificaciones han sido elaboradas teniendo en mente un propósito definido y tomando como base trabajos efectuados en paises exportadores de capitales (22). Las legislaciones de algunos países en desarrolio, como Viet-Nam y Arabia Saudita consideran también a los bienes intangibles como una forma de apor-

18. Brasil, Lex. cit. Artículo 1; Indonesia, Lex cit. Artículo 2, b; Viet-Nam, Lex cit. Artículo 5, 2. c).

19. Régimen Común, cit. Artículo 1\%; Viet-Nam, Lex cit. Artículo 5, 2. c); Indonesia, Lex cit. Artículo 2, b); Argentina, Lex cit. Artículo 2.b).

20. Kenya, Lex cit. Sección 2. (1); Uganda, Lex cit. Sección 5. (1).

21. PHILIPPE KAHN. Rapport Preliminaire, en Report of the Fifty-Second Conference. Helsinki. International Law Association. London, 1966. p. 841.

22. Ibid. p. 842 . 
te de capital (23). Pero, como ha hecho notar el economista Miguel Wionczek (24), "hay razones para creer que en vista del subdesarrollo tecnológico hay numerosas situaciones en que se proporciona a los países receptores de la inversión extranjera privada - contra pagos directos e indirectos de cuantía impresionantela tecnología anticuada, el "know-how" que podria comprarse mucho más barato en condiciones competitivas en otras del mundo". $Y$, añade el mismo autor, que en el caso de empresas extranjeras con participación nacional, "el control real se consigue mediante el control tecnológico que toma forma de acuerdos que suelen prever la exclusividad del aporte de la Tecnología y la división de los mercados" (25).

Aceptar la tecnología como aporte de capital implica, pues, dejar abierta una brecha para acentuar la dependencia hacia los países exportadores de capital. El Régimen Común de Tratamiento a los Capitales Extranjeros de la Comisión del Acuerdo de Cartagena estatuye, por eso, en su artículo 21, que las contribuciones tecnológicas intangibles darán derecho al pago de regalías -es decir podrán comercializarse- pero no podrán computarse como aporte de capital. Mediante el control de la comercialización se trata de evitar algunos de los excesos que serian más difíciles de detectar bajo la forma de inversiones.

\section{Carácter "extranjero" de las inversiones}

El carácter "extranjero" de una inversión se puede determinar por varios criterios.

Por un lado, dentro del criterio tradicional (26), que sostiene que la condición del capital, en cuanto a su "nacionalidad", no deriva de él mismo, sino de la condición de su dueño, puede recurrirse para fijar el carácter de una inversión a la nacionalidad del propie-

23. Viet-Nam, Lex cit. Artículo 5, 2, b; Arabia Saudia, Lex cit. Artículo $1^{\circ}$. Asimismo RICARDO MENDEZ SILVA. Op. cit. p. 13.

24. MIGUEL S. WIONCZEK. Problemas involucrados en el Establecimiento de un Trato Común para la Inversión Extranjera en el Mercado Común Andino (Mimeo) 1970. p. 40. Ver también un amplio tratamiento sobre el tema del mismo autor, Inversión y Tecnología extranjera en América Latina, México, Cuadernos de Joaquín Mortiz, 1971.

25. Ibid. p. 39.

26. RICARDO MENDEZ SILVA. Op. cit. p. 12. tario. Esta es la solución adoptada en el Código de Inversiones de Túnez, en su artículo 20\%, así como en las leyes sobre inversiones de Arabia Saudita artículo 10, y Uganda Sección 1, 1). Esta era la solución seguida en el Perú hasta la promulgación del Decreto-Ley No 18350 . Pero si bien es cierto que determinar la nacionalidad del propietario cuando éste es una persona natural no ofrece mayores dificultades, la situación es distinta y da origen a dilatadas argumentaciones, cuando el propietario es una persona jurídica, llegándose en muchos casos a negar tal nacionalidad por completo (27).

En el Perú el Artículo IX del Título Preliminar del Código Civil parece indicar que las Personas Jurídicas tienen la nacionalidad del pais de constitución; criterio que ha sido el sostenido por la Corte Internacional de Justicia de La Haya en el caso de la Barcelona Traction. Por otra parte las Leyes Nos. 11780 del Petróleo, 13836 sobre Construcciones Navales, 14012 de Empresas de Aviación, 15720 sobre Aeronaútica Civil y el Decreto Supremo № 071-68-HA sobre crédito, consideraban "nacionales" a las compañías cuyo capital social perteneciera en un $60 \%$ a peruanos; al mismo tiempo la Ley № 6207 sobre cabotaje y los Decretos Leyes Nos. 17330 sobre Bancos, en su artículo 2; y 17420 sobre Agentes Marítimos, y el Decreto Supremo 017-69-TC, acerca de Empresas Navieras; consideraban como "nacionales" a compañias cuyo capital social fuese de peruanos en un $75 \%$; y por último - pero en forma simultánea- el artículo 1 ㅇ del Decreto Ley № 17330 sobre Bancos, consideraba como "nacionales", a aquellas compañías cuyo capital perteneciera en su totalidad a personas naturales peruanas $y / o$ personas juridicas que estuviesen constituidas en igual forma. 'El criterio para fijar el carácter del capital era eminentemente político. El Decreto Ley 18900 que ha derogado, a este respecto, los

27. Opiniones de los doctores Alfredo Solf y Muro, Pedro Oliveira, Manuel Augusto Olaechea y Juan José Calle, en las Actas de la Comisión Reformadora del Código Civil Peruano. Lima, 1923. Fascículo I, Sesión 39a. pág. 190. Opiniones de los doctores Carlos García Gastañeta, José Luis Bustamante y Rivero y Alberto Ulloa Sotomayor, en Diario de Sesiones de la Octava Conferencia Internacional Americana. Lima, 1938. p. 344. Ver, también, JOSE LEON BARANDIARAN. Comentarios al Código Peruano. Lima, 1952, p. 91. ROBERTO MAC LEAN. Las Personas Jurídicas en el Derecho Internacional Privado. Lima, 1963. p. 97 y sgts. 
dispositivos citados define como empresa nacional, la constituida en el Perú y cuyo capital pertenezca en más de ochenta por ciento a inversionistas nacionales y siempre que esta proporciór se refleje en la dirección técnica, administrativa y comercial, pero entendiendo como "nacionales" digo diferente al concepto tradicional, conforme se explica más adelante.

Se puede recurrir para fijar el carácter "extranjero" de la inversión, en segundo lugar, no a la nacionalidad del propietario sino a su domicilio o residencia, lo cual es un criterio que se ajusta más a la realidad y es la solución seguida por la Ley No 4131, modificada por la Ley No 4390, de Brasil, en su artículo 19 y por la ley de inversiones de Portugal, en su artículo 19. Pero hay un nuevo criterio, que introducido por primera vez por la legislación peruana, en el Decreto-Ley' No 18350, Ley General de Industrias, fue posteriomente incorporado en otras normas peruanas, $y$ ha terminado por ser adoptado por los países que integran el Aciordo de Cartagena. Este criterio es de carácter económico y en muchos casos independiente de la nacionalidad, aunque vinculado a la residencia del propietario.

En la Parte Cuarta, E, del Decreto-Ley No 18350, Ley General de Industrias, promulgado el 27 de julio de 1970 , se definió por primera vez como capital social nacional el perteneciente a peruanos con un minimo de seis meses al año de residencia en el país, o a extranjeros, aunque no sean residentes. que renuncien a remitir capitales y utilidades fuera del país. Este último aspecto se convirtió en el elemento esencial de la doctrina peruana. El mismo texto fue incorporado al Decreto-Ley No 18810, Ley General de Pesquería, promulgado el 25 de marzo de 1971, en su Parte Sexta, C; pero sufrió algunas transformaciones antes de ser aprobado como texto común para Bolivia, Colombia, Chile, Ecuador y Perú.

El artículo 10 del Régimen Común de Tratamiento a los Capitales Extranjeros de la Comisión del Acuerdo de Cartagena, con la modificación introducida en el Perú por el artículo 1ㅇ del Decreto-Ley No 18999, considera como inversionista nacional -además del Estado, de las personas naturales nacionales, de las personas jurídicas nacionales que no persigan fines de lucro, de las comunidades laborales, y de las empresas constituidas en el país cuyo capital pertenezca en más del ochenta por ciento a inversionistas nacionales y que esta proporción se refleje en la direc- ción técnica, financiera, administrativa y comercial de la empresa- a las personas naturales extranjeras que hayan residido ininterrumpidamente en el pais por no menos de un año $y$, además, renuncien al derecho de reexportar el capital y a transferir utilidades al exterior. No basta, pues, con ser residente como en la doctrina tradicional, ni con renunciar a la exportación del capital y utilidades como en la tesis peruana. Pero es evidente que la característica más importante de la nueva doctrina es la renuncia a la repatriación del capital y de las utilidades, pues de esta forma la inversión se vincula de una manera indisoluble a la economía nacional. Durante el primer año de operaciones del Comité de Inversiones y Tecnologias Extranjeras del Ministerio de Economia y Finanzas, han solicitado su conversión a inversionistas nacionales cuatrocientos sesenta extranjeros, con un capital registrado de mil dieciséis millones, ochocientos cuarenticinco mil, ochocientos cincuentiocho soles, suma que representa el tres por cienio del total de inversiones extranjeras directas en el Perú registradas al 31 de marzo de 1973.

En cuanto a la conversión de inversionistas extranjeros en nacionales se ha debatido en torno a si es posible renunciar a la reexportación de solamente una parte del capital y de las utilidades que este capital produzca, para acogerse a la calificación de inversionista nacional. Sobre tal cuestión el Comité de Inversiones y Tecnologías Extranjeras del Ministerio de Economia y Finanzas, se ha pronunciado sosteniendo que, si bien el Decreto-Ley $N$ ọ 18350 se refería al capital social nacional, que por naturaleza es divisible, y permitía por eso la renuncia parcial, no ocurre lo mismo con el Régimen Común, que se refiere a la calidad de inversionista nacional, que es un estado de la persona y que como tal es indivisible. Además de esta razón, existe la de no permitir que haya una inversićn que reciba el trato de nacional, y que pueda ser administrada en consideración a los intereses de la otra parte del capital que sí goza del trato de inversión extranjera, y cuyo destino final no está vinculado al desarrollo del país sino al beneficio de una economía que opera en función de sus propios intereses. Al redactar los formularios de renuncia a la repatriación del capital y utilidades, el Comité ha incorporacio al texto la renuncia a la repatriación de todo el capital presente y futuro del inversionista.

Correlativamente, la ley entiende como inversionista extranjero al propietario de una inversión extranjera 
directa, tal como se definió más arriba. Queda por aclarar la situación del extranjero que no siendo propietario de una inversión extranjera no es inversionista extranjero y que, por definición, tampoco es inversionista nacional. Algunos bancos locales han exigido, en estos casos, para otorgar crédito por encima de los límites que el Decreto-Ley № 18900 establece para las empresas extranjeras, que se conviertan en inversionistas nacionales, y el Comité de Inversiones y Tecnología Extranjeras del Ministerio de Economía y Finanzas ha aceptado este criterio y en varios casos ha resuelto que procede la conversión a inversionista nacional de extranjeros que no son propietarios de inversión, pero que podrán serlo en el futuro.

\section{Ventajas y desventajas reconocidas a las inversiones extranjeras}

Las inversiones, bajo las formas en que se han producido en los países en vías de industrialización, y en particular dentro de la perspectiva de la historia económica y politica del Perú, han traído consigo una carga casi siempre desbalanceada de ventajas y desventajas. Entre las primeras se encuentra el aporte mismo del capital que permite el acometimiento de empresas, la realización de proyectos y el emprendimiento de obras productivas impostegables para el desarrollo. Al estudiar el periodo de bonanza a mediados del siglo pasado, un autor se ha referido a "la fuerte inyección de capitales extranjeros que recibiera el país a partir de 1869" (28); y aun un escritor tan poco propenso a simpatizar con la penetración del capital extranjero, como lo era Mariátegui, la hacer un análisis de la economía peruana después de la guerra del Pacífico, concedió que las inversiones extranjeras brindaron "alguna ayuda para su convalecencia" (29).

También se admite como ventaja del capital extranjero el conocimiento, tecnología, habilidad gerencial, organización y capacidad administrativa que trae consigo y que para una sociedad en proceso de iniciar su desarrollo significa un aporte tan valioso como el capital mismo. Reconociendo esta aseveración Haya de la Torre escribió, en 1928, que "en estos países la primera forma del capitalismo moderno es la del

28. CARLOS CAMPRUBI ALCAZAR. Historia de los Bancos en el Perú. T. I. Lima, 1957. p. 130.

29. JOSE CARLOS MARIATEGUI, Siete Ensayos de Interpretación de la Realidad Peruana. Tercera Edición, Lima, 1952. p. 24. capital extranjero imperialista" (30). Una tercera ventaja reconocida a la inversión extranjera, y en especial a la vinculada ocn la industria primaria o extractiva, es la de brindar acceso, a través de empresas subsidiarias y asociadas; a un mercado más amplio que al que podría llegar por sí solo el productor nacional, que frecuentemente en los paises no industrializados, tiene alcance a un mercado interno aún demasiado pequeño. Por último, hay también beneficios de carácter marginal que trae el capital extranjero, como pueden ser el aumento de las exportaciones o la disminución de las importaciones, con repercusiones en la balanza de pagos, y el aumento de ocupación para la mano de obra excedente, en la mayoría de los casos con una retribución mejor que la que obtiene el resto de los trabajadores, o que la que obtenía antes el mismo trabajador.

Argumentos más entusiastas de las virtudes del capilal extranjero han llegado a presentar a éste bajo la imagen del caballo regalado, como observara un destacado economista. En el otro platillo de la balanza, mientras tanto, los detractores sostienen que no es un caballo, en absoluto, sino más bien un lobo. con piel de cordero (31).

Entre las desventajas que con más frecuencia se atribuyen al capital extranjero se encuentra la influencia politica que ejerce y que ha llevado a que se denuncie la situación de dependencia, expuesta desde hace varios años en planteamientos aislados, y recientemente como doctrina de interpretación de la realidad socio-económica peruana. Escritores conservadores, como Víctor Andrés Belaúnde, han coincidido con políticos de izquierda en afirmar que "el síntoma más alarmante de la economía peruana ha sido nuestra dependencia del capital extranjero ... en una proporción tal que amenaza nuestra independencia política" (32), y que se refleja en hechos como los producidos en París, cuando en 1971, se reunieron acreedores del Estado peruano para considerar la refinanciación de

30. VICTOR RAUL HAYA DE LA TORRE. El Antiimperialismo y el Apra. Tercera Edición. Lima, 1970, p. 1.

31. MIGUEL S. WIONCZEK. United States Investment and the Development of Middle America. Studies in Comparative International Development. Vol. V, 19691970. Number 1. p. 3.

32. VICTOR ANDRES BELAUNDE. La Realidad Nacional. Segunda Edición. Lima, 1945. pp. 264-265. 
la deuda externa a corto plazo, la que se negaron a otorgar, según comentarios autorizados, en un esfuerzo para obligar al gobierno peruano a abrir las puertas de par en par a los inversionistas extranjeros (33). Comentaristas más radicales, por otro lado, consideran que en el transcurso de los años la situación de dependencia no ha sido disminuido sino que simplemente ha cambiado de apariencia (34).

A consecuencia de la influencia política ejercida a través del capital extranjero se producen fricciones políticas, diplomáticas y sociales, como en los casos del guano, del petróleo y del cobre, hasta crear un clima adverso, que llega muchas veces a reflejarse en novelas como "Redoble por Rancas" o "Garabombo el Invisible" de Manuel Scorza. Por último, se afirma que la inversión extranjera en lugar de aportar capitales al pais, sirve en realidad de drenaje al capital que sale en forma de utilidades, dividendos, intereses y regalías sin ningún control y que, en algunos años, ha superado el monto de inversiones ingresadas.

\section{Conclusión}

El objeto de un trabajo sobre el régimen legal de las inversiones extranjeras en el Perú debe ser comprobar cómo se ha regulado las inversiones, aprovechando las ventajas $y$ neutralizando las desventajas dentro del contexto social y económico del país, y finalmente examinar hasta qué punto se puede lograr un control efectivo de las mismas a través de las instituciones jurídicas tradicionales, y cuando se hace necesario crear órdenes legales que correspondan a los planteamientos de nuestra realidad concreta y actual. En algunos casos, el aporte de capital ha sido ficticio. Ha habido empresas que aportaban al pais di-

33. Diario New York Times de 12 de julio de 1971. p. 39. 34. ANIBAL QUIJANO. Nacionalismo, Neoimperialismo y Militarismo en el Perú. Ediciones Periferia. Buenos Aires. 1971. visas en reducida cantidad y luego obtenian del mercado de capitales interno crédito por diez veces al valor de su aporte. Esta operación daba como resultado que, después del primer año de operaciones, el inversionista extranjero podia sacar del país el capital inicial y continuar trabajando, en adelante, con el ahorro del país. En otros casos, la tecnologia aportada no ha sido de una calidad que pueda competir en condiciones de igualdad con otras técnicas y métodos de organización. $Y$ en cuanto al acceso de los productores locales a los mercados internacionales, los países en vías de desarrollo han comenzado a asumir la comercialización externa de muchos de sus productos.

Muchas veces la situación de dependencia de los países en vías de desarrollo se acentúa no sólo mediante el más ostensible recurso de legislar otorgando privilegios o ventajas a favor de ciertos grupos (35), sino, bajo una forma menos advertida, al aceptar los términos en que se plantea un problema, o a través de conceptos legales como la "nacionalidad" de las sociedades, la "reciprocidad" en el trato a los inversionistas extranjeros con los nacionales, el arbitraje internacional para resolver las disputas sobre inversiones, y las "garantias" a los países inversionistas. Estos conceptos, que han sido creados para ser entendidos dentro del contexto de un sistema económico; social y político determinado, que es el de las naciones altamente desarrolladas, dentro de condiciones estructuralmente distintas y que exigen por ello trato diferente, como es el caso de los países en proceso de desarrollo, producen efectos distorsionados que no se ajustan a la realidad circundante, son fuente de conflicto y resultan inadecuados para alcanzar las melas propuestas en términos de uns distribución más justa de la riqueza.

35. Como se expone en LUIS PASARA, El Rol del Derecho en la Epoca del Guano, Derecho, No 28. 1970. p. 11. 